\title{
Leading With LARCs in Nigeria: The Stars Are Aligned to Expand Effective Family Planning Services Decisively
}

\author{
James D Shelton, ${ }^{a}$ Clea Finkle
}

Despite years of family planning effort in Nigeria, the modern contraceptive prevalence (mCPR) has reached only $10 \%$. Yet a few recent seminal, well-executed programs have been outstandingly successful providing long-acting reversible contraceptives (LARCs) - both in the public and private sector, and in the North and South. Remarkably, the LARCs they provided were equivalent to $2 \%$ mCPR in 2015 alone.

Accordingly, we advocate markedly increased support for: (1) private-sector approaches such as social franchising, particularly in the South, (2) mobile outreach, and (3) support to public clinical facilities, including expanding access through community health extension workers (CHEWs), particularly in the North. Success will require system support, quality, and concerted engagement from a variety of partners including the Government of Nigeria.

Without significant progress in Nigeria, the global FP2020 goal appears unattainable. Fortunately, leading with LARCs along with wide choice of other methods provides a clear avenue for success.

\section{THE VIRTUES OF LARCS-NIGERIA IS NO EXCEPTION}

P rovision of long-acting reversible contraceptives (LARCs)_-IUDs and implants_-has been highly effective, perhaps even revolutionary in the United States, in preventing unintended pregnancy, particularly with adolescents. ${ }^{1}$ No single method, or even 2 methods, can satisfy the diverse needs of all clients, and clients must have good choice and access to a wide variety of methods. Yet those same attributes that have made LARCs so popular in the United States-very high effectiveness, long duration of action, independence of the sex act, generally manageable side effects, potential for use without partner knowledge, and in the case of implants no need for a pelvic exam-appear to have wide appeal in Nigeria. Still, success with LARCs requires more than simple availability of the products. LARCs require service delivery approaches with a higher degree of wherewithal and quality than for shorter-acting methods. But as described below, such LARC-enabling approaches are beginning to thrive in Nigeria.

\footnotetext{
${ }^{a}$ Global Health: Science and Practice, Editor-in-Chief, Washington, DC, USA.

${ }^{b}$ Bill \& Melinda Gates Foundation, Seattle, WA, USA.

Correspondence to James D Shelton (jdshelton@jhu.edu).
}

\section{COMPELLING NEED}

Nigeria looms large in need for family planning. Its current 186 million population is projected to grow to almost 400 million by 2050, a mere 34 years from now. ${ }^{2}$ Its maternal mortality ratio of 576 per 100,000 live births ${ }^{3}$ is among the highest in the world-and far off the Millennium Development Goal (MDG) target of 300. Nigeria also performs poorly on most other health and development indicators, including infant mortality (69 per 1,000 live births), ${ }^{3}$ poverty $(62 \%),{ }^{4}$ and female literacy $(50 \%) .^{5}$ Moreover, there are marked health disparities between the richest and poorest. ${ }^{3}$

\section{DAUNTING CHALLENGES IN FAMILY PLANNING}

Thus far, Nigeria has been rather resistant to family planning efforts. Between 2008 and 2013, the modern contraceptive prevalence rate $(\mathrm{mCPR})$ remained at a mere $10 \%{ }^{2}$ And that use was dominated by shortacting methods. Reported ideal family size is 6.5 children. The health system itself is highly challenged, ${ }^{6}$ and the decentralized federal structure that delegates major functions to its 36 states and the Federal Capital of Abuja as well as to over 770 local government areas (LGAs) makes broad support and management unwieldy. Most people seek health 
LARCs appear to have wide appeal in Nigeria. services from a patchwork of private health care providers. Unfounded rumors about contraceptive methods are believed to be widespread. And women's knowledge about contraception is limited, especially about LARCs. In the 2013 Demographic and Health Survey, only $25 \%$ of married women had even heard of implants and $32 \%$ of IUDs. ${ }^{3}$ Whereas modern contraceptive use in the more rural, less prosperous, and less literate North East and North West states is below $4 \%$, levels are significantly higher in the southern zones, especially in the South West where contraceptive rates in 7 states range from $21 \%$ to $32 \%$.

\section{YET REMARKABLY POSITIVE DEVELOPMENTS}

Despite this difficult backdrop, a diverse set of recent developments provide compelling evidence that family planning efforts are beginning to make significant headway in the country.

- Between 2008 and 2013, 6 states showed gains of 5 to 12 percentage points in modern contraceptive use. ${ }^{3}$

- The Nigerian Urban Reproductive Health Initiative (NURHI) in 4 urban areas increased contraceptive prevalence an average of $11 \%$ in 5 years by combining substantial demandand supply-side efforts, including highly accessible mobile "outreach" services. Over $40 \%$ of those gains came from increased use of LARCs (mostly implants). Misconceptions about contraceptives declined markedly and intent to use contraception increased significantly. ${ }^{7,8}$

IUDs can be a popular choice among postpartum women
- As described in an article in this issue of GHSP, ${ }^{9}$ an immediate postpartum, small-scale initiative with private providers in several states found that $41 \%$ of eligible women who delivered in those facilities received immediate insertion of an IUD-evidence that IUDs can be a popular choice among postpartum women.

- Following the 2012 London Summit on Family Planning, the Government of Nigeria articulated more prominent support for family planning including a detailed and cogent national family planning blueprint with ultra-ambitious objectives, ${ }^{10}$ although actual financial resources provided so far have been limited. Many states have followed suit, with state-level costed implementation plans
(CIPs). Some positive policy reforms have also occurred, notably allowing a basic-level cadre of service health worker-the community health extension worker (CHEW) - to provide implants and IUDs. Additional reforms have included making contraceptives free in publicsector clinics and reforming the nurse/midwife training curriculum to make it proficiencybased and supported by rigorous supervision.

\section{Outstanding Successes With LARCs Specifically}

A range of programmatic approaches in both the private and public sector emphasizing access and quality have achieved strikingly high provision of LARCs in Nigeria. Most are relatively recent:

- The Marie Stopes Nigeria "BlueStar" social franchising program, launched in 2012, supports more than 300 private-sector providers, especially in the South, of whom about $70 \%$ are midwives. They provided a notably large number of women-more than 65,000-with contraception, especially implants, in 2015 (Table).

- The Society for Family Health's Healthy Family Network social franchising program, also with more than 300 providers, has likewise been successful, although in its case more with the IUD (Table).

- A more recent entry to Nigeria, DKT International also gives support to private providers, particularly in the South. Its model consists mainly of marketing contraceptive products to providers and distributors, without the networking and other components of social franchising. LARC sales in 2015-at more than 100,000-are also striking (Table).

- Marie Stopes Nigeria deploys "mobile outreach" teams in the North. Such mobile outreach typically occurs in collaboration with the public sector and in public-sector sites. Remarkably, with only 8 outreach teams, they provided some 63,000 clients with LARCs in 2015, primarily implants (Table).

- Marie Stopes Nigeria also began the Family Health Plus initiative in 2014. It works with public-sector providers at the state level, now expanded to 20 states, emphasizing training, supportive supervision, and supply chain. Again, provision of LARCs to more than 
TABLE. Provision of Long-Acting Reversible Contraceptive Methods by Selected Program Initiatives, Nigeria, 2015

\begin{tabular}{lccc}
\hline Program & Implants & IUDs & Total LARCs \\
\hline BlueStar (Marie Stopes Nigeria) & 51,643 & 13,811 & $\mathbf{6 5 , 4 5 4}$ \\
Healthy Family Network (SFH) & 20,273 & 53,900 & $\mathbf{7 4 , 1 7 3}$ \\
DKT International sales & 15,967 & 87,600 & $\mathbf{1 0 3 , 5 6 7}$ \\
Mobile outreach (Marie Stopes Nigeria) & 53,786 & 9,200 & $\mathbf{6 2 , 9 8 6}$ \\
Family Health Plus (Marie Stopes Nigeria) & 222,705 & 29,686 & $\mathbf{2 5 2 , 3 9 1}$ \\
Total & 364,374 & $\mathbf{1 9 4 , 1 9 7}$ & $\mathbf{5 5 8 , 5 7 1}$
\end{tabular}

Abbreviations: IUDs, intrauterine devices; SFH, Society for Family Health; LARCs, long-acting reversible contraceptives.

Source of data: For Marie Stopes Nigeria, personal communication with Anna Mackay, Deputy Director of SIFPO Project, Marie Stopes International; for SFH, personal communication with Peter Entonu, Associate Director of Social Franchise Unit, SFH; for DKT, sales report from December 2015. ${ }^{11}$

250,000 clients in 2015 is highly impressive (Table).

\section{What Is Particularly Notable About These Findings From the 5 Initiatives?}

- Sizable enough to "move" the needle. More than 550,000 women received LARCs from just these 5 initiatives, representing over $2 \%$ of married women of reproductive age and $1.5 \%$ of all women of reproductive age in Nigeria nationally-a truly impressive proportion (Table). Of course these numbers don't translate directly into contraceptive prevalence. For example, some women would have switched from other methods, and sales do not precisely reflect method provision. Still, the results from just these 5 projects in just 1 year should be enough to register population-level impact. And because LARCs engender high rates of satisfaction and continuation, the sustained cumulative effect over a number of years would be substantial. Some corroboration of such an impact come from the Performance Monitoring \& Accountability 2020 (PMA2020) surveys in Kaduna state in the North-a state where Family Health Plus, Healthy Family Network, Marie Stopes Nigeria mobile outreach, and NURHI (as well as others) are all active. Between 2014 and 2015, the share of overall modern contraceptive use for implants in Kaduna increased from $16 \%$ to $28 \% .^{12}$
- Substantial untapped "latent" demand. While these initiatives appropriately include modest demand-side components, they mainly consist of making contraceptive services highly accessible. Thus, a significant amount of demand for modern contraception among a sizable proportion of women already exists that can be satisfied with good services and a modicum of targeted demand "activation" support.

- LARCs are highly acceptable for women desiring contraception. This is particularly the case for implants, but also for IUDs.

- Promoting equity: LARC programming LARCs serve both serves very low-income as well as low- and highhigher-income clients. For example, client income clients. exit interview data indicate that $75 \%, 53 \%$, and $49 \%$ of Marie Stopes Nigeria's mobile outreach, Family Health Plus, and social franchising clients, respectively, were from households living on less than US\$2.50 per day (personal communication with Anna Mackay, Deputy Director of SIFPO Project, Marie Stopes International).

- Success in both the South and North. While it is generally held that the more conservative North is highly resistant to family planning, these projects - notably, mobile outreach and the Family Health Plus public-sector support project-demonstrate that success can be achieved in the North as well.

- Success in both the private and public sectors. Private-sector approaches including 


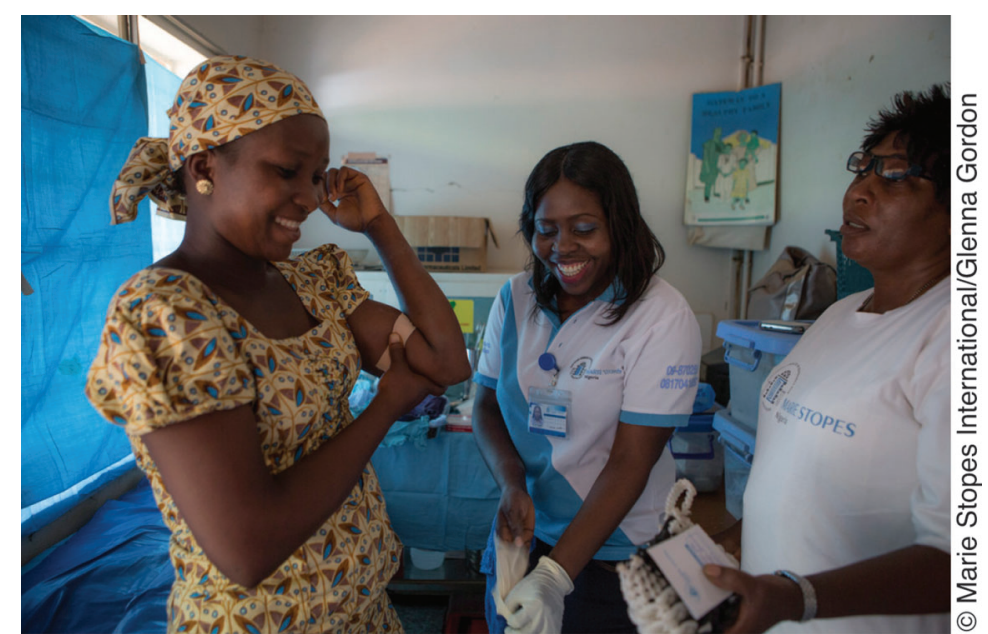

A woman in Nigeria has had a contraceptive implant inserted by providers from Marie Stopes Nigeria.

social franchising align well with the South, which has a large concentration of small private-sector providers and is more economically advanced. But the Family Health Plus experience shows that despite the public sector's reputation as a weak service delivery platform, working closely with state governments on public-sector service delivery can be successful.

In addition to the programming described above, a number of other worthwhile initiatives are ongoing in Nigeria, including traditional social marketing and clinic-based public-sector and NGO services. We are merely highlighting some of the more prominent programs that have been highly successful with LARCs.

\section{Our proposed strategy: Support a diversity of service delivery approaches and wide method choice, including LARCs; emphasize the private sector in the South and the public sector in the North.}

\section{WHAT NEXT: OUR PRIORITIES FOR EXPANDED FAMILY PLANNING PROGRAMMING}

Our proposed overall family planning strategy for Nigeria:

Support a diversity of service delivery approaches and wide method choice, but emphasize the private sector in the South and the public sector in the North. And prioritize service modes that include LARCs effectively.

Family planning is most successful when clients have a wide variety of methods to choose from, and clients can choose from a variety of service delivery sites. Accordingly, it makes strategic sense to pursue diverse programming efforts in both the public and private sector across the country, emphasizing those models that have a good track record. Recognizing that about $60 \%$ of contraceptive use nationally comes from the private sector, private/commercialsector approaches such as social franchising are particularly well-suited for the South where of the very wide distribution of private-sector providers and the entrepreneurial climate. However, in the North, where that private-sector infrastructure is currently thin, priority should be with the public and NGO sectors. It also seems reasonable to be opportunistic by working most with states that are willing to commit more of their own resources. Since LARCs, especially implants, are so clearly popular and satisfy the needs of many clients well, it is wise to invest in service delivery modes that can provide LARCs effectively, along with a broad range of methods including injectables. Building on the successful models described above, we present some details of this strategy.

Social franchising. Current efforts in social franchising have been highly successful as described above, and indeed in a wide variety of other countries, and they should be expanded markedly, particularly in the South.

Mobile outreach. Although so far small in scale, mobile outreach has been shown to be highly effective already, particularly in the most difficult part of the country-the North and for hard-to-reach rural populations. But this proven approach should also be deployed in other areas such as urban slums and peri-urban areas generally. Notably, it was part of the highly effective urban NUHRI project in the North and South.

Expanded provision of LARCs and injectables by CHEWs, particularly in the public sector. Having CHEWs provide LARCs has been shown to be effective in research studies ${ }^{13}$ and now presents a major opportunity for mainstream service delivery expansion, given the recently liberalized policy to permit it. A first order of activity is to scale-up training and supportive supervision for CHEWs to provide LARCs, thus nurturing "dedicated providers" who, in turn, become mentors to new providers. CHEWs have many other duties, however, and some will be more motivated to provide LARCs than others. Thus, finding a way to provide good 
support to the most productive CHEWs is essential. Provision of injectables by CHEWs should be a complementary priority, especially in the North where CHEWs are often the main or only clinical providers.

Social marketing, especially focusing on injectables. The successful model DKT is following deserves considerable expansion. An additional opportunity is extending provision of injectables through the many qualified proprietary patent medicine vendors (PPMVs) in both the North and the South. Heretofore, PPMVs have not been permitted to provide injectables. However, a recent PPMV census found that over half in Northern states and about 30\% in Southern states were staffed by trained professionals including nurses, pharmacists, and CHEWs. ${ }^{14}$ Since CHEWs are now permitted to provide injectables (and implants) in the public sector, it seems entirely reasonable that PPMVs trained as CHEWs or nurses should also be permitted to give injectables. Sayana Press, the version of DMPA delivered subcutaneously via the prefilled Uniject device, is also being introduced in Nigeria, which offers a variety of advantages and additional potential for expanded injectable use.

Postpartum contraception, especially IUDs and implants. The results with immediate postpartum IUDs provided by private-sector providers described above are very promising. Nationally, 36\% of women deliver in facilities, with significantly higher rates of facility delivery in the South compared with the North. ${ }^{3}$ Especially for high-volume facilities where providers are more likely to retain skills, immediate postpartum insertion of IUDs or later provision of IUDs, implants, or other methods before discharge can be an important component of programming. ${ }^{15}$ Moreover, providing contraception later in the postpartum period, for example, along with immunization services, can be highly effective for reaching women during this time of very high unmet need. ${ }^{16}$ And mobile outreach in conjunction with child immunization services can successfully reach women in the postpartum period.

\section{Key System Support Priorities}

In addition to the priority program approaches described above, serious attention is needed to the following system support activities.
Demand support. The programmatic approaches we propose benefit markedly from a healthy component of demand activation, including community engagement to promote awareness and to address specific issues such as misconceptions about contraception. In addition, broader demand support such as through mass media is a compelling priority, addressing key issues such as social norms and the health benefits of birth spacing.

Supply chain. Family planning cannot suc- Family planning ceed without functional supply chains. The cannot succeed current variably functioning public-sector supply without functional chain depends not only on the federal govern- supply chains. ment but on states and LGA support as well. It will require considerable additional attention. One progressive innovation is the "informed push" model to help ensure good distribution, which has been successfully piloted in Nigeria. ${ }^{17,18}$ Private-sector distribution, such as for social franchising, can use a more commercialsector type of supply chain approach capitalizing on the economic incentive, since participants along the chain are paying for the commodity. LARCs have the distinct advantage over shorteracting methods that they do not require frequent resupply. On the other hand, they do requirea modest but important amount of equipment and disposable supplies such as gloves and disinfectants, which require additional supply attention.

Human resources. The "2014 Nigeria Family Planning Blueprint" lays out the major challenges: lack of staff, lack of training, high turnover, and uneven geographic distribution in the public sector, ${ }^{10}$ all of which need to be addressed systematically. Progressive task shifting will help. A major advantage of private-sector providers is that many are underemployed. Thus, making good use of private-sector CHEWs and qualified PPMVs to give injectables should be a high priority.

Policy and advocacy. Advocacy is needed at both the federal level and the state level toward meaningful funding for family planning. Again, key policy reforms, such as permitting trained pharmacists and PPMVs to provide injectables would make a considerable difference.

Monitoring and evaluation. Nigeria is fortunate that PMA2020 will be expanding its annual surveys from 2 states to 7, beginning this year (personal communication with Scott Radloff, Director, PMA2020). Priority should be given to support policy makers and program managers to 
improve data use to enable course correction and decisions about resource allocation in those states.

Emerging primary health care platforms. The Government of Nigeria has recently resolved to strengthen primary health care overall, ${ }^{6}$ and donors such as the U.S. Agency for International Development (USAID), the Department for International Development (DFID), and the Bill \& Melinda Gates Foundation are providing significant support for such platforms in selected states. This emphasis should be a good opportunity to advance family planning services, but only if sufficient resources are forthcoming and key preventive services such as family planning are given high priority. A key opportunity would be inclusion of a robust set of family planning services under the planned national health insurance scheme. ${ }^{19}$

\section{LEADING WITH LARCS - THE TIME IS NOW}

The evidence is clear that family planning efforts not only can be successful-but are being successful-in Nigeria, especially through provision of LARCs. Nigeria is a large and complex country and ultimate success will require substantial resources, long-term attention, and a variety of approaches. Yet as we have seen, providing LARCs when done well with the proper service delivery wherewithal can be remarkably effective. Investments in these modes will go a substantial distance to meet client needs, stem unintended pregnancies, reduce maternal mortality, and support Nigeria's national family planning goals as well as the FP2020 global goal. Success will require substantial commitment, engagement, and partnership across the board, including the Government of Nigeria. The time is right for a substantial investment in Nigeria. Do not let this compelling opportunity pass by.

Acknowledgments: We appreciate the invaluable help from Jennifer Anyanti, Alan Bornbusch, Effiom Effiom, Peter Entonu, Onoriode Ezire, Marguerite Farrell, Moriam Jagun, Stephen Hodgins, Patricia MacDonald, Anna Mackay, Emmanuel Otolorin, Christopher Purdy, and Scott Radloff.

Competing Interests: None declared.

\section{REFERENCES}

1. McNicholas $C$, Peipert JF. Long-acting reversible contraception for adolescents. Curr Opin Obstet Gynecol. 2012;24(5):293-298. CrossRef. Medline

2. United Nations (UN), Department of Economic and Social Affairs, Population Division. World population prospects, the 2015 revision. New York: UN; 2015. Available from: http://esa.un. org/unpd/wpp/Download/Probabilistic/Population/

3. National Population Commission (NPC) [Nigeria]; ICF International. Nigeria demographic and health survey 2013. Abuja (Nigeria): NPC; 2014. Co-published by ICF International. Available from: https://dhsprogram.com/pubs/pdf/FR293/ FR293.pdf

4. World Bank Open Data [Internet]. Washington (DC): The World Bank Group; c2016. Poverty headcount ratio at national poverty lines (\% of population); [cited 2016 Apr 3]. Available from: http://data.worldbank.org/indicator/SI.POV.NAHC/countries/ NG? display=graph

5. World Bank Open Data [Internet]. Washington (DC): The World Bank Group; c2016. Adult literacy rate, population 15+ years, both sexes (\%); [cited 2016 Apr 3]. Available from: http://data. worldbank.org/indicator/SE.ADT.LITR.ZS/countries/TJ? display $=$ graph

6. Green A. Experts skeptical about Nigeria's free health-care plans. Lancet. 2016;387(10023):1044. CrossRef. Medline

7. Measurement, Learning \& Evaluation (MLE) Project; National Population Council (NPC); Data, Research and Mapping Consult, Ltd. Measurement, learning \& evaluation of the Urban Reproductive Health Initiative: Nigeria 2014 endline survey. Chapel Hill (NC): MLE Project; 2015. Available from: https:// www.urbanreproductivehealth.org/sites/mle/files/mle_twp22015_nigeria.pdf

8. Krenn S, Cobb L, Babalola S, Odeku M, Kusemiju B. Using behavior change communication to lead a comprehensive family planning program: the Nigerian Urban Reproductive Health Initiative. Glob Health Sci Pract. 2014;2(4):427-443. CrossRef. Medline

9. Eluwa GIE, Atamewalen R, Odogwu K, Ahonsi B. Success providing postpartum intrauterine devices in private-sector health care facilities in Nigeria: factors associated with uptake. Glob Health Sci Pract. 2016;4(2):276-283. CrossRef

10. Ministry of Health (MOH) [Nigeria]. Nigeria family planning blueprint (scale-up plan). Abuja (Nigeria): $\mathrm{MOH} ; 2014$. Available from: http://www.healthpolicyproject.com/ns/docs/ CIP_Nigeria.pdf

11. DKT International. Monthly sales report-Dec 2015. Washington (DC): DKT International; 2015. Available from: http://www. dktinternational.org/wp-content/uploads/2013/06/December2015-Sales-Report.pdf

12. Performance Monitoring \& Accountability 2020 (PMA2020). PMA2015/Kaduna-R2. Baltimore (MD): PMA2020; 2015. Available from: http://pma2020.org/sites/default/files/NGR2KADUNA-FPBrief-v10-2015-12.08.pdf

13. Charyeva Z, Oguntunde O, Orobaton N, Otolorin E, Inuwa F, Alalade $\mathrm{O}$, et al. Task shiffing provision of contraceptive implants to community health extension workers: results of operations research in Northern Nigeria. Glob Health Sci Pract. 2015;3 (3):382-394. CrossRef. Medline

14. Liu J, Prach LM, Treleaven E, Hansen M, Anyanti J, Jagha T, et al. The role of drug vendors in improving basic health-care services in Nigeria. Bull World Health Organ. 2016;94(4):267-275. CrossRef. Medline

15. Gaffield ME, Egan S, Temmerman M. It's about time: WHO and partners release programming strategies for postpartum family planning. Glob Health Sci Pract. 2014;2(1):4-9. CrossRef. Medline

16. Dulli LS, Eichleay M, Rademacher K, Sortijas S, Nsengiyumva T. Meeting postpartum women's family planning needs through integrated family planning and immunization services: results 
of a cluster-randomized controlled trial in Rwanda. Glob Health Sci Pract. 2016;4(1):73-86. CrossRef. Medline

17. Daff $B M$, Seck $C$, Belkhayat $H$, Sutton P. Informed push distribution of contraceptives in Senegal reduces stockouts and improves quality of family planning services. Glob Health Sci Pract. 2014;2(2):245-252. CrossRef. Medline

18. Watson N, McCord J. Evaluating last-mile distribution systems in Nigeria. Arlington (VA): USAID I DELIVER
PROJECT, Task Order 4; 2015. Available from: http://deliver.jsi.com/dlvr_content/resources/allpubs/ countryreports/NG_EvalLastMile.pdf

19. Lawyers Alert [Internet]. Makurdi (Nigeria): Lawyers Alert. The Nigeria National Health Act 2014: snap review; 2015 Jan 26 [cited 2016 May 3]. Available from: https://lawyersalert. wordpress.com/2015/01/26/the-nigeria-national-health-act2014-snap-review/

First Published Online: 2016 May 19

Cite this article as: Shelton JD, Finkle C. Leading with LARCs in Nigeria: the stars are aligned to expand effective family planning services decisively. Glob Health Sci Pract. 2016;4(2):179-185. http://dx.doi.org/10.9745/GHSP-D-16-00135

(c) Shelton and Finkle. This is an open-access article distributed under the terms of the Creative Commons Attribution License, which permits unrestricted use, distribution, and reproduction in any medium, provided the original author and source are properly cited. To view a copy of the license, visit http://creativecommons.org/licenses/by/3.0/. When linking to this article, please use the following permanent link: http://dx.doi.org/10.9745/GHSP-D-16-00135. 